\title{
Efficient synthesis of functionalized 2-pyridones by ytterbium chloride catalyzed tandem condensation
}

\author{
WANG QianNan, YAO ZhiGang, XU Fan* \& SHEN Qi* \\ Key Laboratory of Organic Synthesis, College of Chemistry, Chemical Engineering and Materials Science, Soochow University, Suzhou 215123, \\ China
}

Received March 15, 2011; accepted May 31, 2011; published online February 21, 2012

\begin{abstract}
An efficient method was developed for the synthesis of arylidene heterobicyclic 3-cyano-2-pyridones via ytterbium chloride catalyzed tandem condensation of aromatic aldehydes, cyclic ketones, and cyanoacetamide. The conditions and scope of the reaction were investigated and a reaction mechanism was proposed.
\end{abstract}

pyridone, ytterbium chloride, tandem reaction, catalysis, synthesis

Citation: Wang Q N, Yao Z G, Xu F, et al. Efficient synthesis of functionalized 2-pyridones by ytterbium chloride catalyzed tandem condensation. Chin Sci Bull, 2012, 57: 1612-1615, doi: 10.1007/s11434-011-4744-0

Tandem reactions are powerful methods for the synthesis of structurally complex compounds from simple substrates. Among the strategies used for the construction of biologically active molecules, tandem reactions for the design and synthesis of drug-like compounds are of particular interest to organic synthetic chemists. The 2-pyridone skeleton is an important substructure found in many natural or synthetic biologically active materials, and its derivatives have been applied in various pharmaceutical and biochemical fields. It is of great interest that specifically functionalized 2pyridones may possess specific biological properties. For example, milrinone [1] (Scheme 1, A), which has a 3-cyano-2-pyridone core, is an effective cardiotonic agent. More recently, antitumor screening data showed that some fused 3-cyano-2-pyridones with an arylidene moiety [2] (Scheme 1, B) are potential antitumor agents. These findings indicate that efficient methods need to be developed for the synthesis of these 3-cyano-2-pyridones. According to the rather limited literature in this area, arylidene heterobicyclic 3-cyano-2-pyridones were synthesized in the presence of a base in a stepwise manner, with the necessary intermediates such as $\alpha, \alpha$ '-bis(arylidene)cycloalkanones or

*Corresponding authors (email: xufan@ suda.edu.cn; qshen@suda.edu.cn)<smiles>Cc1[nH]c(=O)c(C#N)cc1-c1ccncc1</smiles>

A<smiles>COC(C)(C)Oc1c2c([nH]c(=O)c1C#N)/C(=C/C(C)=O)CN(C)C2</smiles>

B
Scheme 1

2-cyano-3-phenylacrylates prepared and isolated in advance [2-7].

Lanthanide reagents have been increasingly applied and widely studied in organic synthesis in recent years [8-11]. Most of the lanthanides are nontoxic and relatively abundant in nature. The successful development of many useful reactions efficiently catalyzed by lanthanide compounds can be attributed to the unique features of lanthanide centers, such as their high electrophilicity, variable metal ion radius and tunable coordination patterns. Prompted by our previous studies on lanthanide halide-catalyzed synthesis of biologically relevant heterocyclic compounds [12-16], we investigated the effectiveness of lanthanide chlorides as catalysts 
for the tandem preparation of arylidene heterobicyclic 3-cyano-2-pyridones. This type of synthesis is very important and attractive from the viewpoints of operational simplicity and assembly efficiency. Herein, we report our preliminary results from this investigation.

An initial trial was conducted with a three-component condensation of cyclopentanone 1a, benzaldehyde $\mathbf{2 a}$ and cyanoacetamide $\mathbf{3}$ (Scheme 2 ) in the presence of a catalytic amount of ytterbium chloride $\left(\mathrm{YbCl}_{3}\right)$, which is a readily available and economical lanthanide Lewis acid. To our surprise, 7-benzylidene-3-cyano-4-phenyl-3,4,6,7-tetrahydro$1 H$-cyclopenta[b]pyridin-2(5H)-one $4 \mathbf{a}$ was obtained rather than the expected 7-benzylidene-3-cyano-4-phenyl-6,7dihydro- $1 H$-cyclopenta $[b]$ pyridin- $2(5 H)$-one 5a. The structure of $\mathbf{4 a}$ was determined by ${ }^{1} \mathrm{H}$ NMR spectroscopy. This compound produced four doublets at $\delta 5.02(0.5 \mathrm{H}, J=7.5$ $\mathrm{Hz}), 4.77(0.5 \mathrm{H}, J=12.6 \mathrm{~Hz}), 4.36(0.5 \mathrm{H}, J=12.6 \mathrm{~Hz})$ and $4.13(0.5 \mathrm{H}, J=7.5 \mathrm{~Hz})$, which indicates that there are two protons at 3- and 4-position of this 2-pyridone. According to the literature [2-7], the relevant multistep reactions all afforded $\mathbf{5 a}$ as a major product under basic conditions. Consequently, the use of $\mathrm{YbCl}_{3}$ as a Lewis acid-type catalyst in the present reaction can be considered a key factor affecting the structure of product, and the reaction mechanism may be different in acidic and basic conditions.

The following reaction conditions for the model reaction were then investigated: catalyst loading, reaction time, reaction temperature, and solvent. The results are listed in Table 1. When the catalyst loading was increased from $5 \mathrm{~mol} \%$ to $20 \mathrm{~mol} \%$ the yield increased considerably, but the further increase in the catalyst loading did not improve the yield. Among the solvents screened, ethanol gave the best result. Several lanthanide chlorides were tested to assess the influence of the central metal on the catalytic activity. The order of catalytic activity was $\mathrm{Yb}>\mathrm{Y} \approx \mathrm{Er}>\mathrm{La}$, which is the reverse order to the ionic radii of these lanthanides. Thus, $\mathrm{YbCl}_{3}$ was chosen as the representative lanthanide catalyst and the optimum reaction conditions were established for subsequent experiments. In a typical experimental procedure, $\mathbf{1 a}(2 \mathrm{mmol}), \mathbf{2 a}(3 \mathrm{mmol})$ and $\mathrm{YbCl}_{3}(0.3 \mathrm{mmol})$ were mixed and heated at $120^{\circ} \mathrm{C}$ for $6 \mathrm{~h}$. Then $3(2 \mathrm{mmol})$ and ethanol $(4 \mathrm{~mL})$ were added. The resulting mixture was refluxed for $24 \mathrm{~h}$. The yellow precipitate was filtered and washed with EtOH and water to afford the target product $\mathbf{4 a}$.

To examine the scope and generality of this method, the process was extended to various aromatic aldehydes and cyclic ketones under the optimum reaction conditions (Scheme 3). As summarized in Table 2, the method was equally effective for five-membered and six-membered cyclic ketones and all the reactions proceeded smoothly affording the desired arylidene heterobicyclic 3-cyano-2pyridones in moderate to good yields. The reaction could also be used for aromatic aldehydes with ortho-, meta- and para-substituents, and tolerated both electron deficient and rich aldehydes.

A byproduct was isolated from the crude product of our model reaction, which was characterized as $\alpha, \alpha$-dibenzylidene cyclopentanone $\mathbf{C}$ and should be produced from benzaldehyde and cyclopentanone. This finding directed us to a plausible mechanism. It can be suggested that the first step of the present reaction is probably a Lewis acid-catalyzed cross-aldol condensation of aldehyde with ketone to produce $\mathbf{C}$, which is similar to the $\mathrm{Yb}(\mathrm{OTf})_{3}$ catalyzed reaction described by Wang et al. [17]. The Michael addition of cyanoacetamide to $\mathbf{C}$ leads to $\mathbf{D}$, which subsequently eliminates water and cyclizes to form the product (Scheme 4). To confirm this mechanism, a supplementary experiment was carried out using $\alpha, \alpha$-dibenzylidene cyclopentanone $\mathbf{C}$ as the substrate. $\mathbf{C}$ was mixed with cyanoacetamide and $\mathrm{YbCl}_{3}$ (20 $\mathrm{mol} \%)$ and the resulting mixture was stirred in $\mathrm{EtOH}$ under reflux for $70 \mathrm{~h}$. After work up, product 4a was obtained in $75 \%$ yield, indicating that $\mathbf{C}$ was the key intermediate in this tandem condensation process.

In conclusion, an efficient route was developed for the<smiles>N#Cc1c(-c2ccccc2)c2c([nH]c1=O)/C(=C/c1ccccc1)CC2=Cc1ccccc1</smiles>

Scheme 2

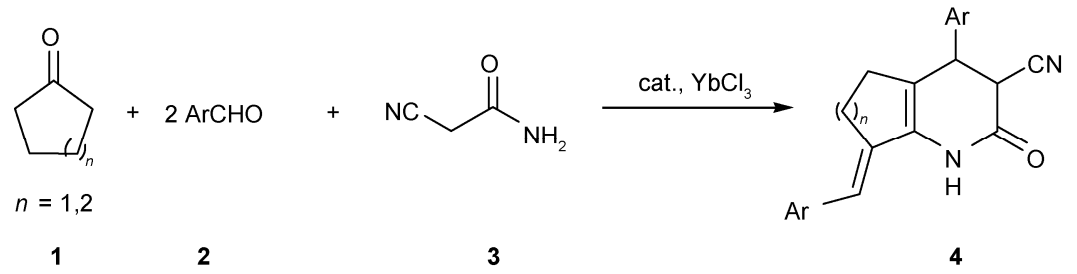


Table 1 Screening of reaction conditions for the tandem condensation of cyclopentanone, benzaldehyde and cyanoacetamide ${ }^{\text {a) }}$

\begin{tabular}{ccccccc}
\hline Entry & Catalyst & Loading $(\mathrm{mol} \%)$ & Temperature $\left(T_{1} / T_{2}\right)^{\mathrm{b})}\left({ }^{\circ} \mathrm{C}\right)$ & Solvent & Time $\left(t_{1}+t_{2}\right)^{\mathrm{c})}(\mathrm{h})$ & Yield $(\%)$ \\
\hline 1 & $\mathrm{YbCl}_{3}$ & 5 & $120 / 90$ & EtOH & $6+24$ & 17 \\
2 & $\mathrm{YbCl}_{3}$ & 10 & $120 / 90$ & EtOH & $6+24$ & 42 \\
3 & $\mathrm{YbCl}_{3}$ & 15 & $120 / 90$ & EtOH & $6+24$ & 62 \\
4 & $\mathrm{YbCl}_{3}$ & 20 & $120 / 90$ & EtOH & $6+24$ & 75 \\
5 & $\mathrm{YbCl}_{3}$ & 25 & $120 / 90$ & EtOH & $6+24$ & 75 \\
6 & $\mathrm{YbCl}_{3}$ & 20 & $100 / 90$ & EtOH & $6+24$ & 68 \\
7 & $\mathrm{YbCl}_{3}$ & 20 & $120 / 90$ & EtOH & $2+24$ & 57 \\
8 & $\mathrm{YbCl}_{3}$ & 20 & $120 / 90$ & EtOH & $6+70$ & 79 \\
9 & $\mathrm{YbCl}_{3}$ & 20 & $120 / 70$ & THF & $6+24$ & 5 \\
10 & $\mathrm{YbCl}_{3}$ & 20 & $120 / 120$ & DMF & $6+24$ & 6 \\
11 & $\mathrm{YbCl}_{3}$ & 20 & $120 / 90$ & Toluene & $6+24$ & 44 \\
12 & $\mathrm{LaCl}_{3}$ & 20 & $120 / 90$ & EtOH & $6+24$ & 37 \\
13 & $\mathrm{ErCl}_{3}$ & 20 & $120 / 90$ & EtOH & $6+24$ & 62 \\
14 & $\mathrm{YCl}_{3}$ & 20 & $120 / 90$ & EtOH & $6+24$ & 64 \\
\hline
\end{tabular}

a) Reaction conditions: 1a, 2a and catalyst were mixed and heated at temperature $T_{1}\left({ }^{\circ} \mathrm{C}\right)$ for time $t_{1}(\mathrm{~h})$. Then $\mathbf{3}$ and solvent were added and the resulting mixture was heated at temperature $T_{2}\left({ }^{\circ} \mathrm{C}\right)$ for time $t_{2}(\mathrm{~h})$. b) The first temperature is for $T_{1}$ and the second temperature is for $T_{2}$. c) The first time is for $t_{1}$ and the second time is for $t_{2}$.

Table $2 \mathrm{YbCl}_{3}$-catalyzed condensation of cyclic ketones, aromatic aldehydes and cyanoacetamide ${ }^{\mathrm{a})}$

\begin{tabular}{|c|c|c|c|c|}
\hline Entry & Cyclic ketone & $\mathrm{Ar}$ & Product & Yield (\%) \\
\hline 1 & & $\mathrm{Ph}$ & $4 a$ & 75 \\
\hline 2 & & 4-ClPh & $4 b$ & 80 \\
\hline 3 & & $3-\mathrm{CH}_{3} \mathrm{OPh}$ & $4 c$ & 82 \\
\hline 4 & & 3-FPh & $4 d$ & 77 \\
\hline 5 & & $2-\mathrm{CH}_{3} \mathrm{Ph}$ & $4 e$ & 76 \\
\hline 6 & & 2-ClPh & $4 f$ & 62 \\
\hline 7 & & $\mathrm{Ph}$ & $4 \mathrm{~g}$ & 65 \\
\hline 8 & & 4- $\mathrm{CH}_{3} \mathrm{OPh}$ & $4 h$ & 63 \\
\hline 9 & & $4-\mathrm{CH}_{3} \mathrm{Ph}$ & $4 i$ & 74 \\
\hline 10 & & 4-BrPh & $4 j$ & 78 \\
\hline 11 & & 4-FPh & $4 k$ & 70 \\
\hline 12 & & 3-FPh & 41 & 70 \\
\hline 13 & & $4-\mathrm{CH}_{3} \mathrm{OPh}$ & $4 m$ & 65 \\
\hline 14 & $=\mathrm{O}$ & 4-ClPh & $4 n$ & 77 \\
\hline 15 & & 4-BrPh & 40 & 88 \\
\hline
\end{tabular}

a) Reaction conditions: 1:2:3 $=0.67: 1: 0.67,10 \mathrm{~mol} \% \mathrm{YbCl}_{3}$ relative to aromatic aldehyde. $\mathbf{1}, \mathbf{2}$ and $\mathrm{YbCl}_{3}$ were mixed and heated at $120^{\circ} \mathrm{C}$ for $6 \mathrm{~h}$. Then 3 and EtOH were added and the resulting mixture was refluxed for $24 \mathrm{~h}$.

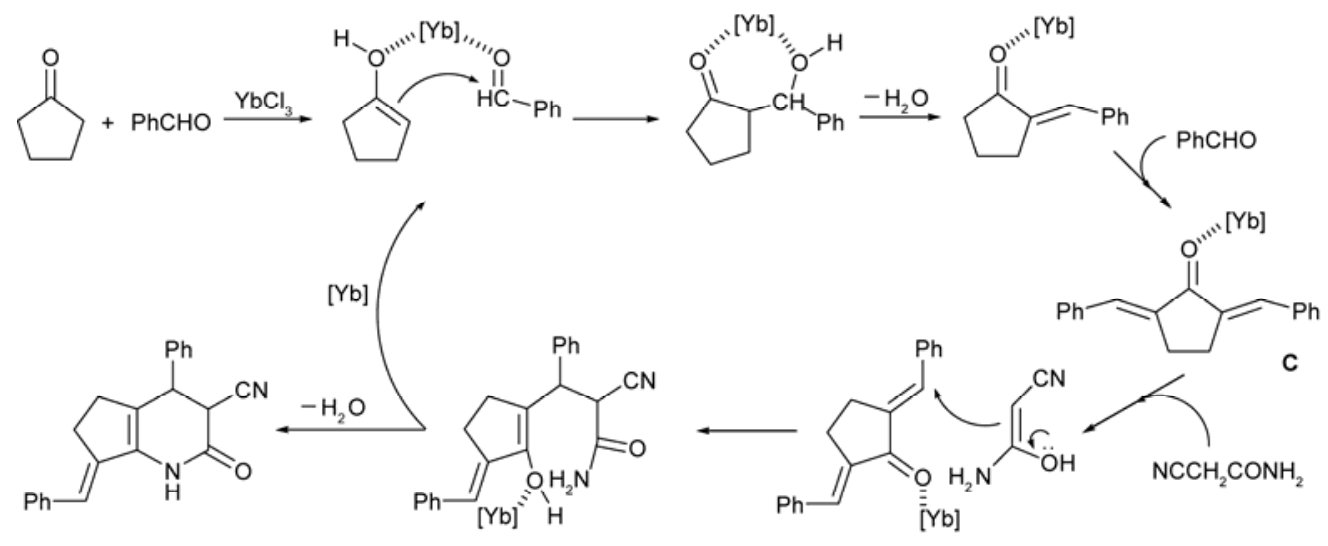


synthesis of arylidene heterobicyclic 3-cyano-2-pyridones via tandem condensation of aromatic aldehydes, cyclic ketones, and cyanoacetamide with $\mathrm{YbCl}_{3}$ as a catalyst. This reaction is atom-economic and can be performed easily. Further applications of this tandem method to the synthesis of biologically active azaheterocyclic compounds are in progress in our laboratory.

This work was supported by the National Natural Science Foundation of China (20872106, 20972107).

1 Robertson D W, Beedle E E, Swartzendruber J K, et al. J Med Chem, 1986, 29: 635-640

2 EI-Subbagh H I, Abu-Zaid S M, Mahran M A, et al. J Med Chem, 2000, 43: 2915-2921

3 Koji S, Satoshi K, Akio S, et al. Synthesis, 1981, 211-213
4 Shestopalov A M, Sharanin Y A. Zhurnal Organicheskoi Khimii, 1986, 22: 1291-1297

5 Shestopalov A M, Sharanin Y A. Zhurnal Organicheskoi Khimii, 1986, 22: 1163-1168

6 Otto H H. Monatsh Chem, 1978, 109: 681-693

7 Jain R, Roschangar F, Ciufolini M A. Tetrahedron Lett, 1995, 36: 3307-3310

8 Molander G A, Romero J A C. Chem Rev, 2002, 102: 2161-2185

9 Kobayashi S, Sugiura M, Kitagawa H, et al. Chem Rev, 2002, 102: 2227-2302

10 Hong S, Marks T J. Acc Chem Res, 2004, 37: 673-686

11 Shibasaki M, Matsunaga S. Chem Soc Rev, 2006, 35: 269-279

12 Han X Y, Xu F, Luo Y Q, et al. Eur J Org Chem, 2005, 15001503

13 Zhou Z Q, Xu F, Han X Y, et al. Eur J Org Chem, 2007, 5265-5269

14 Zhang H H, Zhou Z Q, Yao Z G, et al. Tetrahedron Lett, 2009, 50: $1622-1624$

15 Ji X F, Cai L J, Yao Z G, et al. Heteroatom Chem, 2010, 21: 89-95

16 Yao L B, Xu F, Qi S. Chin Sci Bull, 2010, 55: 4108-4111

17 Wang L, Sheng J, Tian H, et al. Synthesis, 2004, 3060-3064

Open Access This article is distributed under the terms of the Creative Commons Attribution License which permits any use, distribution, and reproduction in any medium, provided the original author(s) and source are credited. 